ENCYCLOPEDDE Encyclopédie berbère

BERBERE

32 | 2010

32 | Mgild - Mzab

\title{
Mohand ou El Haj / Mḥnd u Lhažž (Maroc)
}

M. Peyron

\section{OpenEdition}

Journals

Édition électronique

URL : https://journals.openedition.org/encyclopedieberbere/618

DOI : 10.4000/encyclopedieberbere.618

ISSN : 2262-7197

\section{Éditeur}

Peeters Publishers

\section{Édition imprimée}

Date de publication : 31 décembre 2010

Pagination : 5045-5047

ISBN : 978-90-429-2369-0

ISSN : $1015-7344$

\section{Référence électronique}

M. Peyron, « Mohand ou El Haj / Mḥnd u Lḥažž (Maroc) », Encyclopédie berbère [En ligne], 32 | 2010 ,

document M123, mis en ligne le 11 novembre 2020, consulté le 17 février 2022. URL : http://

journals.openedition.org/encyclopedieberbere/618; DOI : https://doi.org/10.4000/

encyclopedieberbere.618

Ce document a été généré automatiquement le 17 février 2022.

(c) Tous droits réservés 


\title{
Mohand ou El Haj / Mḥnd u Lḥažž (Maroc)
}

\author{
M. Peyron
}

Personnage politico-religieux d'envergure régionale, il s'agit d'un des marabouts (igurramn) du Maroc central, qui, après la mort en 1918 de Sidi 'Ali Amhaouch, dans la mouvance duquel il se situait, prit ses distances vis-à-vis des Ayt Sidi 'Ali, et chercha à s'affirmer en tant que chef spirituel de la résistance contre la pénétration militaire française, ceci au détriment de Sidi Lmekki, fils aîné du grand thaumaturge.

Originaire, dit-on (Guillaume, p. 229), des Ayt Messad de la Moulouya, ou encore des Ayt Yahya d'après Le Glay (p.33), qui nous en a laissé un souvenir assez précis dans l'ensemble, bien que quelque peu romancé, on sait assez peu de ses origines. Toujours est-il que par son intelligence et son loyalisme, dans l'entourage de Sidi 'Ali Amhaouch, il semble avoir gagné la confiance de ce dernier au point d'occuper le rôle d'adjoint, en apparence tout désigné pour succéder au grand homme. Sidi Lmekki et ses frères ne l'entendant pas de cette oreille, ce fut la rupture (Le Glay, p. 32 ; Guennoun, p. 181). Désormais, les Ayt Sidi 'Ali se sont cantonnés dans Bou Wattas et le haut Asif-n-Wirine, tandis que Mohand, lui, se concentrait sur son fief, délimité grosso modo par le triangle Aghbalou-n-Serdane / Sidi Yahya ou Youssef / Tounfit. Un observateur de l'époque signale une réunion chez les résistants de la région, à la fin mai 1922, où, affichant un comportement de chef résolument jusqu'au-boutiste, Mohand aurait fait taire ceux de ses collègues qui parlaient de soumission (Holmström, p. 164). Il s'efforça dès lors coûte que coûte de "faire l'union des musulmans contre les Français » (Guennoun, 1933, p. 310) en Haute Moulouya.

3 En accord avec cette optique unitaire, il est exact qu'en 1922, il rencontra un chef maraboutique voisin, Si Mohammed ben Taïbi, bien que leur réunion n'eut guère de résultats concrets ; il prêta aussi un court moment son soutien au chérif Ben Aomar des Ayt Sgougou, jusqu'à la défaite honteuse de celui-ci devant le poste d'Alemsid en 1923 (Guennoun, p. 263; Guillaume, p. 229); et au printemps de 1929, en sa zaouïa de Sidi Yahyaou-Youssef (Voinot, p. 403), il reçut Ou-Sidi, le chérif de Tilmi, en vue d'ébaucher 
une action commune des tribus contre l'avancée française dans le Haut Ziz - ce qui débouchera sur le sanglant épisode des Ayt Ya'qoub (Peyron 1995, p. 5).

Personnage ambitieux, certes, mais plutôt haut en couleurs, assez peu guerrier, on se souvient de lui en tant que « marabout aux longs cheveux, amateur de femmes " (Huré, p. 13-14); effectuant la tournée des souks de la haute Moulouya en galante compagnie (Raynal, p. 297); faisant croire à l'échec futur des irumin aux « soukiers » des Ayt Yahya du seul fait qu'un avion français de reconnaissance se fût éloigné après un bref survol (Le Glay, p. 33). Travers qui devait immanquablement lui attirer la satire des bardes (Roux, p. 207). D'autant plus qu'au terme d'une courte résistance à la zaouïa Sidi Yahyaou-Youssef, en juin 1931 (Guillaume, p.31), sa reddition était venue consacrer sa déconfiture.

Déconfiture qui ne sera pas définitive et complète, puisque qu'une vingtaine d'années plus tard, c'est son fils qui recevra en leur zaouïa un voyageur visitant la région en roulotte (Bonjean, p. 137).

\section{BIBLIOGRAPHIE}

BONJEAN F., Le Maroc en roulotte, Paris, Hachette, 1950.

GUENNOUN S., La montagne berbère : les Zaïans et le pays Aït Oumalou, Rabat, Omnia, 1933.

GUILlaume A., Les Berbère marocains et la pacification de l'Atlas central (1912-1933), Paris, R. Julliard, 1946.

HOLMSTRÖM M., Un pays de gel et de soleil : au Maroc avec un officier suédois, Paris, Berger-Levrault, 1930.

HURÉ A., La Pacification du Maroc (Dernière étape : 1931-34), Paris : Berger-Levrault, 1952.

LE GLAY M., Itto, récit marocain d'amour et de bataille, Paris : Plon, 1923.

PEYRON M., « Tradition orale et résistance armée : la bataille des Ayt Yâqoub (Haut Atlas, 1929) », EDB, 12, 1995, p. 5-16.

PEYRON M., « Combattants du Maroc central : une résistance morcelée (1912-1933) », AWAL, Cahiers d'études berbères, 16, 1997, p. 25-41.

RAYNAL R., « La terre et l'homme en Haute Moulouya », BESM, 24, 1961, p. 281-346.

Roux A., « Quelques chants berbères sur les opérations de 1931-1932, dans le Maroc central », EDB, 9, 1992, p. 165-219.

VOINOT L., Sur les traces glorieuses des Pacificateurs du Maroc, Paris : Charles-Lavauzelle, 1939.

\section{INDEX}

Mots-clés : Biographie, Chef, Colonisation, Histoire militaire, Maroc, Moyen-Atlas 